Research Article

\title{
Investigation of the Mechanical Behavior of Partially Precast Partially Encased Assembled Composite Beams
}

\author{
Liufeng Zhang $(\mathbb{D}$ and Yinghua Yang \\ School of Civil Engineering, Xi'an University of Architecture and Technology, Xi'an 710055, China \\ Correspondence should be addressed to Liufeng Zhang; zhangliufeng@live.xauat.edu.cn
}

Received 30 June 2019; Accepted 2 August 2019; Published 27 August 2019

Academic Editor: Marco Corradi

Copyright (c) 2019 Liufeng Zhang and Yinghua Yang. This is an open access article distributed under the Creative Commons Attribution License, which permits unrestricted use, distribution, and reproduction in any medium, provided the original work is properly cited.

\begin{abstract}
In view of the characteristics of a high floor and the heavy load of logistics buildings, a partially prefabricated partially encased assembled composite beam (PPEC) is proposed in order to achieve the low cost construction of such buildings. In this research, the mechanical properties of PPEC beams were studied experimentally. The effects of the concrete strength grade, steel content, shear span ratio, and fabrication methods on the mechanical properties of the PPEC beams were analyzed. The results showed that the proposed structural form of the PPEC beams was generally feasible. Based on the test results, a practical shear formula for PPEC beams was proposed, and the calculated results were in good agreement with the test results.
\end{abstract}

\section{Introduction}

In China, e-commerce is gradually changing peoples' lifestyles. With the prosperity of e-commerce, the logistics industry has achieved leapfrog development. The rise of the logistics industry has promoted the concept of logistics buildings. Logistics parks, which are flourishing all over China, which are composed of typical logistics buildings. A remarkable feature of a logistics building is its heavy load. However, under the heavy load of a traditional cast-in-place structure, the design of the horizontal members is often controlled by deflection rather than strength, which will lead to large cross-sections, high reinforcement ratios, and poor economic benefits. In view of this situation, the use of steelconcrete composite beams with high rigidity and high strength is a sensible choice for reducing construction costs. Another characteristic of a logistics building is a high floor height. The traditional cast-in-place structure popular in China needs a large amount of scaffolding and formwork, especially for a relatively high scaffolding project, which is very costly. Therefore, an unsupported construction method is a reasonable way to reduce the cost of construction. In conclusion, an assembled steel-concrete composite structure system is more suitable for the construction of logistics buildings.

Some scholars have carried out a series of studies on the assembled steel-concrete composite structure system. The SR-PC (a frame structure composed of steel reinforced precast concrete members) method proposed by the Japanese Prefabricated Building Association [1] and the FSRPC (a frame structure composed of steel beams and concrete columns) structure system of the Fujita Corporation of Japan involve the research and development of these types of construction systems. In China, Li et al. [2] proposed an integrated steel reinforced concrete frame system with a dog-bone connection at the beam end and explored the influence of the beam-end dog-bone connection on the seismic performance of the joint. Song et al. $[3,4]$ proposed a precast steel reinforced concrete frame system with a steel connection in the beam-column joint area, which simplified the beam-column connection procedure of a precast concrete frame. However, these fully assembled reinforced concrete systems have slightly poor overall performance characteristics, such as slightly less seismic performance than cast-in-place structures to some degree. In addition, the installation accuracy of the fully assembled components is 
high and the lifting weight is large, which greatly increases the project cost. In order to remedy the above shortcomings, this paper proposes a partially precast partially encased assembled composite beam (PPEC) for a logistics building, in order to achieve the low cost construction of these types of buildings.

Before introducing PPEC beams, PEC (partially encased composite) beams and the research for these beams are briefly introduced. Partially encased beams are elements in which the web of the steel section is encased with reinforced concrete $[5,6]$. The web encasement not only brings good fire resistance but also improves the stiffness and bearing capacity without increasing the cross section [7-12]. PPEC beams are improved from PEC beams. A PPEC beam consists of precast and cast-in-place parts. The precast parts of PPEC beams are shown in Figure 1. The construction of a logistics park can change the construction sequence of buildings. Toad construction is carried out first, then the site formed by the road is used to make onsite precast parts, and continuous turnover steel formwork is used to make on-site production in order to further save the cost of the transportation of precast components and the cost of precast components production, and to greatly reduce the cost of construction. After the precast section is completed, it is hoisted in place and then poured into the slab concrete to form a complete beam-slab system (Figure 2).

The PPEC beam proposed in this paper can be designed as unsupported construction due to the existence of I-steel, and the integral pouring of beam-slab concrete can increase the integrity. This beam has great potential advantages for simplifying construction technology and reducing project cost, and it has good prospects for promotion. Therefore, it is necessary to study the mechanical properties of this new composite beam and provide a reference for its engineering applications.

\section{Experimental Program}

2.1. Beam Specimens. A total of sixteen specimens were designed, including six flexural specimens, eight shear specimens, and two cast-in-place contrast specimens. T-shaped beams with flanges were used in all the specimens. The web width of each T-shaped composite beam was $150 \mathrm{~mm}$, the web height of each flexural specimen was $170 \mathrm{~mm}$, and the web height of each shear specimen was $150 \mathrm{~mm}$. The width and the thickness of the concrete flange slab for each specimen were $650 \mathrm{~mm}$ and $80 \mathrm{~mm}$, respectively. Each I-steel beam was welded by Chinese steel (brand Q235), each upper flange width was $100 \mathrm{~mm}$, and each lower flange width was $150 \mathrm{~mm}$. In all the specimens, the distance between the upper flange of the I-beam and the slab surface of the T-shaped composite beam was $50 \mathrm{~mm}$, and all specimens were reinforced with HRB335 steel bars. The diameter of the longitudinal rebar was $12 \mathrm{~mm}$ and that of the slab rebar was $8 \mathrm{~mm}$. The diameters of the stirrups in all specimens were $8 \mathrm{~mm}$ except for one shear specimen (PPEC-7-S) with $10 \mathrm{~mm}$ stirrups. The concrete strength grades of the test beams were C20, C30, and C40. The prefabricated part of the PPEC beam was composed of prefabricated $u$-shaped concrete and a steel skeleton, wherein the steel skeleton was composed of I-steel, longitudinal reinforcement, and stirrups. The design parameters of the specimens are shown in Table 1, and the mechanical properties of the concrete and steel are shown in Table 2 (Figure 3).

2.2. Specimen Production. First, the unequal flange I-beam was forged, and then the polystyrene board with the corresponding thickness was adhered to the upper part of the web and so that it clung to the top flange. Second, the prepared semiclosed stirrups were put into the I-steel one at a time. Third, the longitudinal bars are placed in the stirrup hooks along the length of the I-steel and fixed in place. Fourth, the template was supported and the concrete was poured to complete the precast parts. Fifth, when the precast part reached the predetermined strength, the castin-place part was made. The supporting template, the binding plate reinforcement, and the pouring concrete were completed in turn. This process is illustrated in Figure 4 .

2.3. Test Set-Up and Loading Process. The test was completed on a $500 t$ pressure-testing machine. The test used a fourpoint symmetrical loading method. The distribution beam was placed under the jack to transfer the load evenly to the top of the test piece. The loading device is shown in Figure 5. During the loading process, the vertical load, displacement, and strain of the concrete and steel were mainly monitored. A monotonic static grading loading system was adopted in the test, as follows: First, the load was applied at the rate of $10 \mathrm{kN}$ per step. Then, the load was reduced to $5 \mathrm{kN}$ per step when $90 \%$ of the predicted cracking load was reached. After the specimen cracked, the load was taken as $20 \mathrm{kN}$ per step. When approximately $90 \%$ of the estimated ultimate capacity was reached for the specimens, the load was reduced to $5 \mathrm{kN}$ per step. When the ultimate load was reached, the specimen was continuously loaded to failure.

2.4. Failure Modes of the Specimens. Under the influence of the shear span ratio, the sixteen beam specimens usually presented bending and shear failure modes. The shear span ratio caused the shear failure to be mainly divided into shearcompression failure and cable-stayed failure. The bending failure was a typical bending failure mode. The failure modes of the specimens are shown in Figure 6.

For beams subjected to bending failure, there was no significant difference in the failure modes between the PPEC specimens and the PEC specimens. Figure 7 shows the bending moment-rotation curve of the specimens with a bending failure mode, where the bending moment was $\mathrm{P} / 2$ multiplied by the length of the shear span, and the rotation angle $\theta$ was the midspan displacement divided by the halfspan length. As can be seen in Figure 7, the stiffness of the PEC beams was slightly greater than that of the PPEC beams, but they all showed good deformation capacity. For beams 

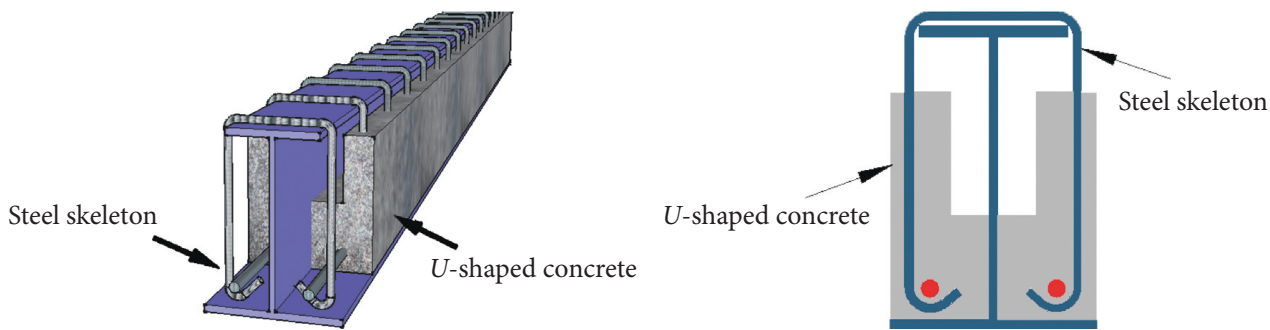

Figure 1: Prefabricated partial configuration.
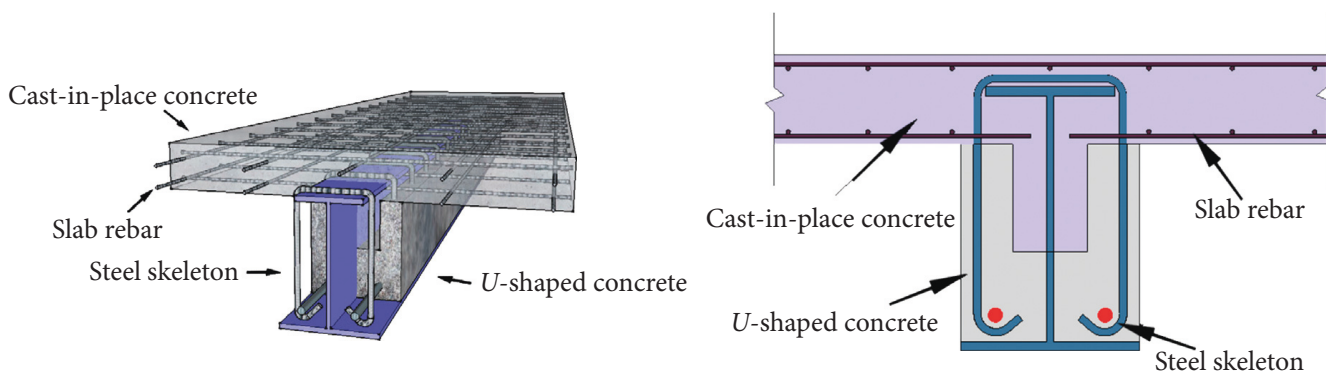

FIgURE 2: Complete beam-slab system.

TABLE 1: Design and test results of the specimens.

\begin{tabular}{|c|c|c|c|c|c|c|c|c|}
\hline \multirow[t]{2}{*}{ No. } & \multirow{2}{*}{$\begin{array}{l}\text { Shear span } \\
\text { length }(\mathrm{mm})\end{array}$} & \multirow{2}{*}{$\begin{array}{l}\text { Shear span } \\
\text { ratio }\end{array}$} & \multirow{2}{*}{$\begin{array}{c}\text { Steel } \\
\text { ratio (\%) }\end{array}$} & \multirow{2}{*}{$\begin{array}{r}\text { Concrete } \\
\text { strength }\end{array}$} & \multirow[t]{2}{*}{ Stirrup } & \multirow{2}{*}{$\begin{array}{l}\text { Ultimate } \\
\text { load }(\mathrm{kN})\end{array}$} & \multicolumn{2}{|c|}{$\begin{array}{l}\text { Bearing } \\
\text { capacity }\end{array}$} \\
\hline & & & & & & & $\mathrm{Mu}$ & $\mathrm{Vu}$ \\
\hline PPEC-1-M & 650 & 2.6 & 7.01 & C30 & B8@150 & 402.75 & 130.89 & - \\
\hline PPEC-2-M & 650 & 2.6 & 8.28 & $\mathrm{C} 30$ & B8@150 & 463.50 & 150.64 & - \\
\hline PPEC-3-M & 650 & 2.6 & 9.55 & $\mathrm{C} 30$ & B8@150 & 468.13 & 152.14 & - \\
\hline PPEC-4-M & 650 & 2.6 & 8.28 & $\mathrm{C} 20$ & B8@150 & 421.55 & 137.00 & - \\
\hline PPEC-5-M & 650 & 2.6 & 8.28 & $\mathrm{C} 40$ & B8@150 & 453.50 & 147.39 & - \\
\hline PPEC-6-M & 650 & 2.6 & 8.28 & C30 & B8@150 & 382.40 & 124.28 & - \\
\hline PEC-7-M & 650 & 2.6 & 8.28 & $\mathrm{C} 30$ & B8@150 & 488.75 & 158.84 & - \\
\hline PPEC-1-S & 400 & 2.0 & 6.84 & C30 & B8@200 & 428.25 & - & 214.13 \\
\hline PPEC-2-S & 400 & 2.0 & 7.76 & C30 & B8@200 & 527.88 & - & 263.94 \\
\hline PPEC-3-S & 500 & 2.5 & 6.84 & C30 & B8@200 & 399.38 & - & 199.69 \\
\hline PPEC-4-S & 300 & 1.5 & 6.84 & C30 & B8@200 & 464.13 & - & 232.07 \\
\hline PPEC-5-S & 400 & 2.0 & 6.84 & $\mathrm{C} 40$ & B8@200 & 513.75 & - & 256.88 \\
\hline PPEC-6-S & 400 & 2.0 & 6.84 & $\mathrm{C} 20$ & B8@200 & 407.25 & - & 203.63 \\
\hline PPEC-7-S & 400 & 2.0 & 6.84 & $\mathrm{C} 30$ & B10@200 & 452.63 & - & 226.32 \\
\hline PPEC-8-S & 400 & 2.0 & 6.84 & C30 & B8@100 & 476.88 & - & 238.44 \\
\hline PEC-9-S & 400 & 2.0 & 6.84 & C30 & B8@200 & 478.75 & - & 239.38 \\
\hline
\end{tabular}

Note. The stirrups of the PPEC-6-M specimens were in the form of welded tie rods between the upper and lower flanges. The shear span length refers to the horizontal distance between the loading point and the adjacent support, and the shear span ratio is the length of the shear span divided by the height of the composite beam.

with a shear failure mode, considering the difference of the specimen lengths, the shear-rotation curves of the specimens are given in Figure 8 . The rotation angle of the specimens was defined as the ratio of the displacement of the loading point to the length of the shear span. The shear span ratio reflected the relationship between the bending and shearing to some degree, which affected the shear failure mode of the PPEC beams. When the shear span ratio was between 1.5 and 2.5, the shear-compression failure of the PPEC beams occurred. When the shear span ratio was greater than or equal to 2.5, the specimens experienced cable-stayed failure. However, unlike the shear brittle failure of the RC (reinforced concrete) beams, the PPEC beams exhibited excellent ductility. The load-rotation curve of the shear specimens is shown in Figure 8.

From Figures 7 and 8, it can be seen that the specimens showed three distinct stages of failure under loading, which could be roughly divided into three stages: elastic, elastoplastic, and plastic failure. Due to the existence of the I-steel, there was no clear turning in the load-rotation 


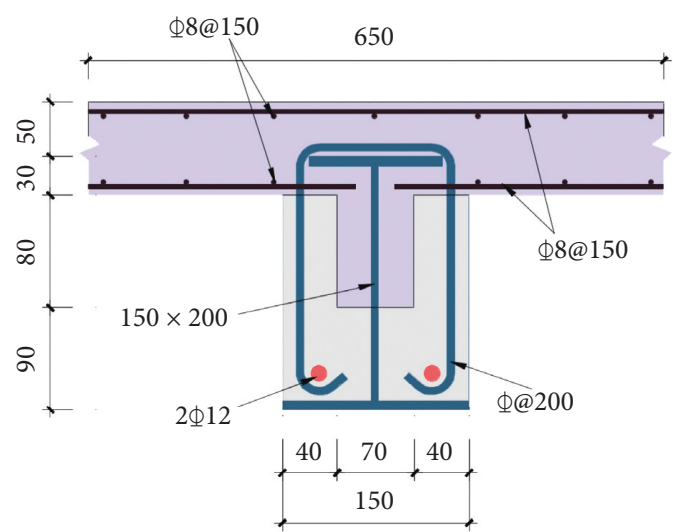

(a)

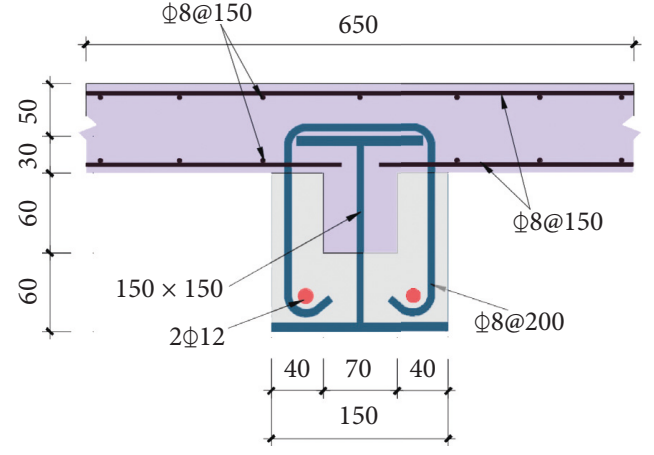

(b)

FIGURE 3: Cross-sectional feature information of the PPEC beam.

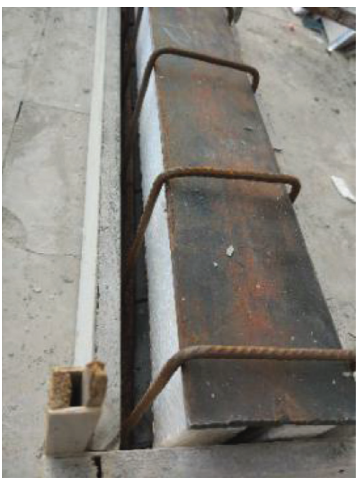

(a)

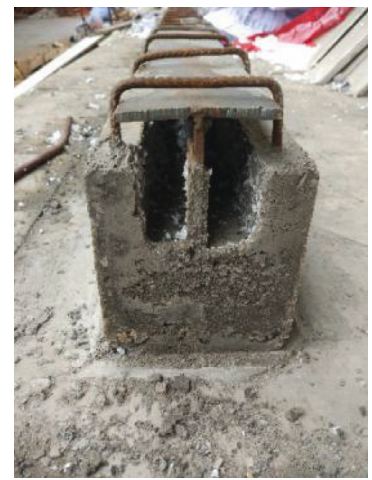

(b)

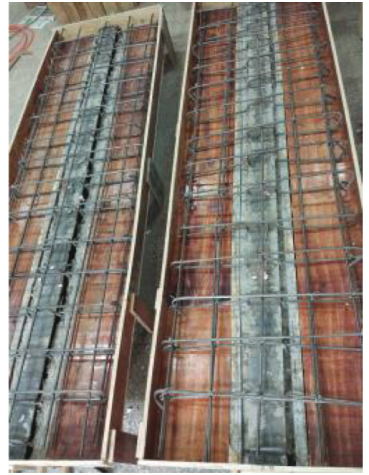

(c)

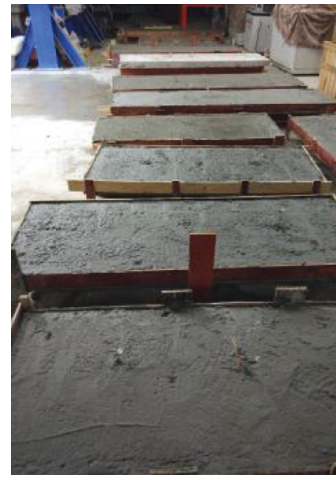

(d)

Figure 4: Construction process of the specimens. (a) Preparation of prefabricated parts. (b) Completed prefabricated parts. (c) Preparation of cast-in-place parts. (d) Completed cast-in-place parts.

TABLE 2: Measured value of material mechanical performance index.

\begin{tabular}{|c|c|c|c|c|c|c|}
\hline \multicolumn{4}{|c|}{ Mechanical properties of steel } & \multicolumn{3}{|c|}{ Mechanical properties of concrete } \\
\hline Steel form & Specifications $(\mathrm{mm})$ & $f_{\mathrm{y}}(\mathrm{MPa})$ & $f_{\mathrm{u}}(\mathrm{MPa})$ & Concrete strength $(\mathrm{MPa})$ & $f_{\mathrm{cu}, \mathrm{pr}}(\mathrm{MPa})$ & $f_{\mathrm{cu}, \mathrm{po}}(\mathrm{MPa})$ \\
\hline \multirow{4}{*}{ Steel plate } & 4 & 276.5 & 453 & \multirow{2}{*}{$\mathrm{C} 20$} & \multirow{2}{*}{21.0} & \multirow{2}{*}{20.6} \\
\hline & 6 & 287.0 & 442.0 & & & \\
\hline & 8 & 279.2 & 421.0 & \multirow{2}{*}{ C30 } & \multirow{3}{*}{23.9} & \multirow{3}{*}{22.6} \\
\hline & 10 & 308.0 & 410.0 & & & \\
\hline \multirow{3}{*}{ Rebar } & 8 & 192.0 & 273.0 & \multirow{3}{*}{$\mathrm{C} 40$} & & \\
\hline & 10 & 200.8 & 302.6 & & \multirow[t]{2}{*}{36.3} & \multirow[t]{2}{*}{35.0} \\
\hline & 12 & 194.0 & 234.5 & & & \\
\hline
\end{tabular}

Note. In the specifications, the steel plate refers to the thickness and the rebar refers to the diameter.

curve before and after the cracks occurred in the specimen. With the yielding and slipping of the lower flange of I-steel, the specimen entered the elastoplastic stage, and the turning angle obviously increased. However, the applied load still has room for further improvement. After loading to the peak load, the flexural specimens were accompanied by concrete crushing in the top compression zone of the slab, the shear specimens were accompanied by concrete crushing in the web, and the specimens were subsequently declared damaged.

\section{Main Influencing Factors of the Bearing Capacity}

The experimental results showed that the typical failure modes of the PPEC beam members could be divided into bending failure and shear failure. The performances of the PPEC beam members under the two failure modes were quite different. The mechanical properties of the beam members were related to the shear span ratio, concrete strength grade, and steel ratio because they determined the 


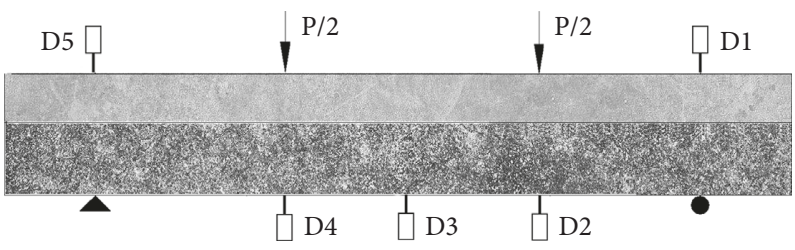

Figure 5: Test set-up and measuring point layout of beam specimens.

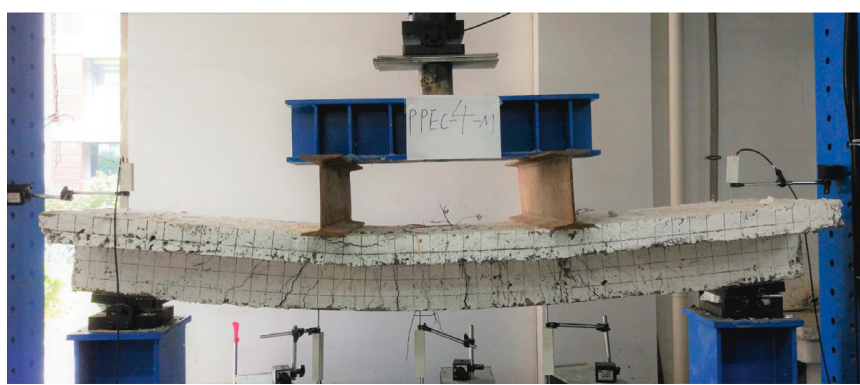

(a)

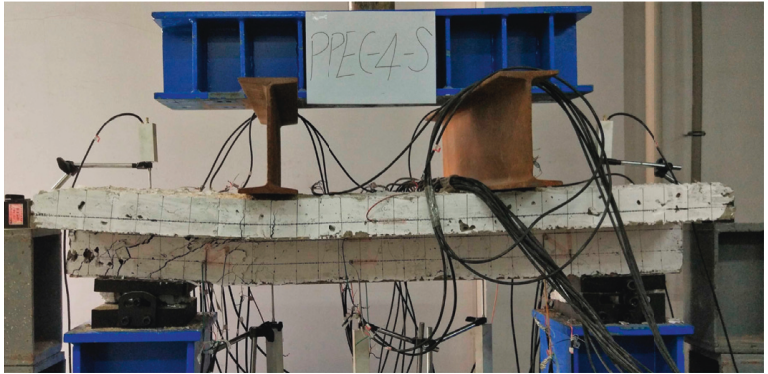

(b)

FIgURE 6: Typical failure modes. (a) Bending failure. (b) Shear-compression failure.

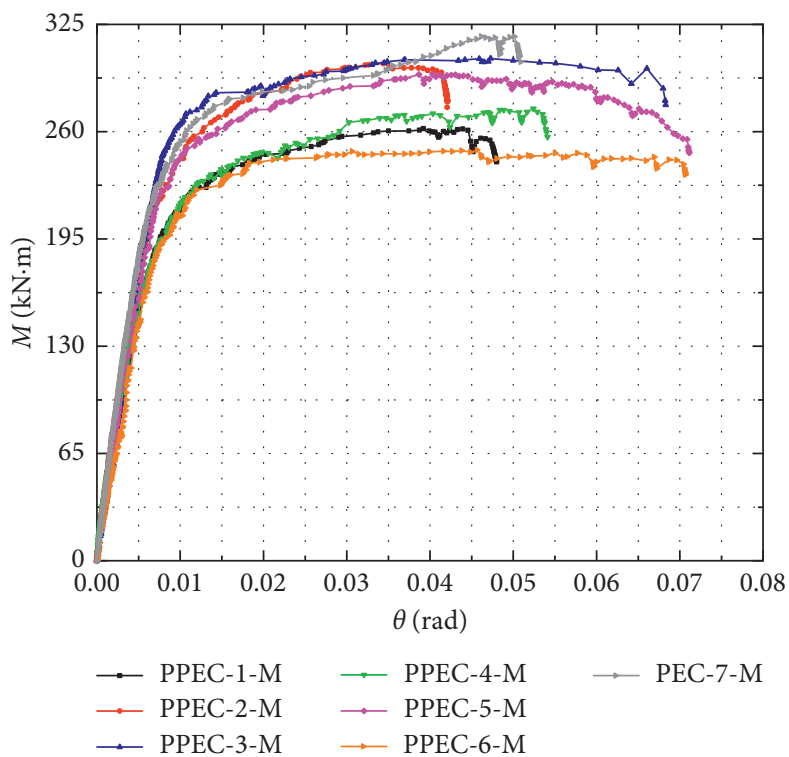

Figure 7: Moment-rotation curves at the midspans of the specimens.

interaction between the I-steel and the concrete to some degree and then they affected the failure mode and the bearing capacity of the members. The concrete strength and the steel ratio had a significant impact on the shear resistance and the bending performance of the beam. The shear properties of the beams were more sensitive to the shear span ratio and the stirrup ratio, and the flexural properties of the beams were more sensitive to the stirrup mode.

3.1. Concrete Strength. The influence of concrete strength on the bearing capacity of the PPEC beams is shown in Figure 9. The research showed that the shear capacity of PPEC beams

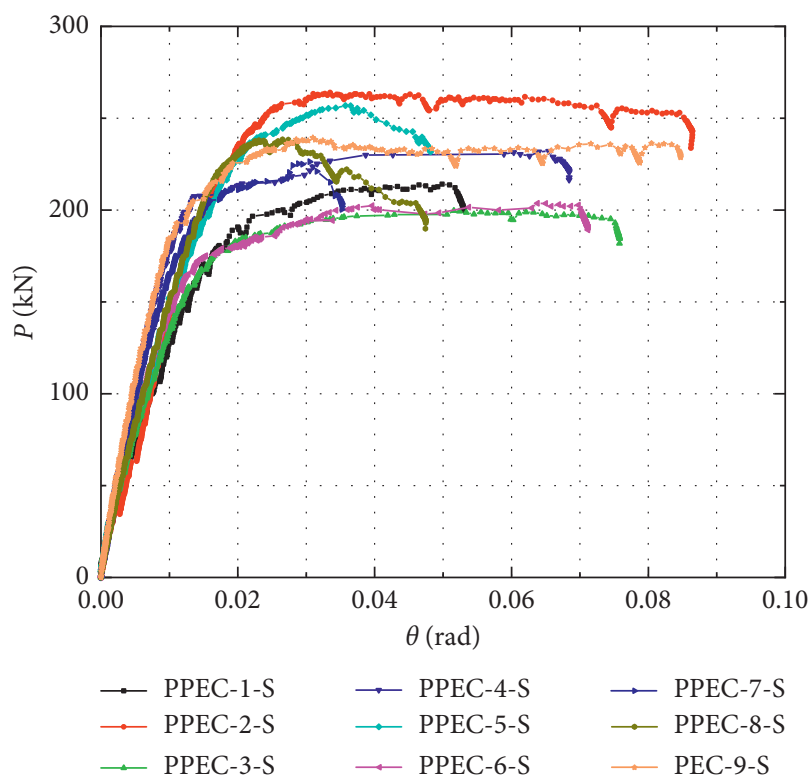

FIGURE 8: Shear force-rotation curves of the specimens.

increased with the increase of the concrete strength. The flexural capacity increased with the increase of the concrete strength in the C20-C30 stage, but it decreased slightly in the C30-C40 stage. In theory, the flexural capacity should increase with the increase of concrete strength grade, but this needs further test verification.

3.2. Steel Ratio. With special instructions, it was shown that the change of steel ratio referred to the change of the flange thickness of the I-steel for the flexural specimens and to the change of the web thickness of the I-steel for the shear specimens. Figure 10 shows the effect of the steel ratio on the 
bearing capacity of the PPEC beams. It can be seen that as the steel ratio increased, its bearing capacity increased gradually. In addition, as the steel ratio increased, the improvement of the flexural capacity of the PPEC beams became smaller and smaller. The reason for this was that as the steel ratio increased, the shear and flexural capacity of the I-steel increased continuously, and then the shear and flexural capacities of the PPEC beam were improved to some degree.

3.3. Shear Span Ratio. Figure 11 shows the influence of the shear span ratio on the shear capacity of the PPEC beams. The results show that the shear span ratio had a significant effect on the shear capacity of PPEC beams, and they show an inverse relationship. Specifically, when $1.5 \leq \lambda<2.5$, shear-compression failure occurred in the PPEC beams, and when $2.5<\lambda$, cable-stayed failure occurred easily in the PPEC beams. In addition, due to the three-sided restraint effect of the I-steel flange on the concrete in the PPEC beams, the compression softening of the concrete in the shear span zone was effectively alleviated, and the shear capacity and the ductility of the PPEC beams were higher than those of the RC beams.

3.4. Stirrup Ratio. Figure 12 shows the effect of the stirrup ratio on the shear capacity of the PPEC beams. As shown in Figure 11, the order of the shear capacity of the PPEC beams was PPEC-1-S $<$ PPEC-7-S $<$ PPEC-8-S. The shear capacity of the PPEC beams increased gradually with the increase of the stirrup ratio. This showed that the increase of the stirrup ratio could increase the shear capacity of the PPEC beams, and the reason was that the increase of the stirrup ratio led to the increase of the stirrup area, which increased the shear capacity of the stirrups and further improved the shear capacity of the PPEC beams.

3.5. Stirrup Form. The test results showed that the stirrups had a significant effect on the flexural capacity of the PPEC beams, and the flexural capacity of the semiclosed stirrups was approximately $21.2 \%$ higher than that of tie-rod PPEC beams. The details are shown in Figure 13. This was most likely due to the weakening of the effective cross-sectional area of the I-steel flange by the welded tie rods, but the effect needs further study.

3.6. Construction Technology. Figure 14 shows the comparison of the bearing capacity between the integrally cast PEC beams and the partially precast PPEC beams. For shear specimen and the flexural specimen, the bearing capacity of the PEC specimen was slightly higher than that of the PPEC specimen. The flexural capacity of the PPEC beams was $5.16 \%$ lower than that of the PEC beams, and the shear capacity of the PPEC beams was $10.55 \%$ lower than that of the PEC beams. This was because the PPEC beam concrete was constructed twice, so the integrity of the interface between the new and old concrete was not as good as that of a one-time casting. However, the differences in the flexural

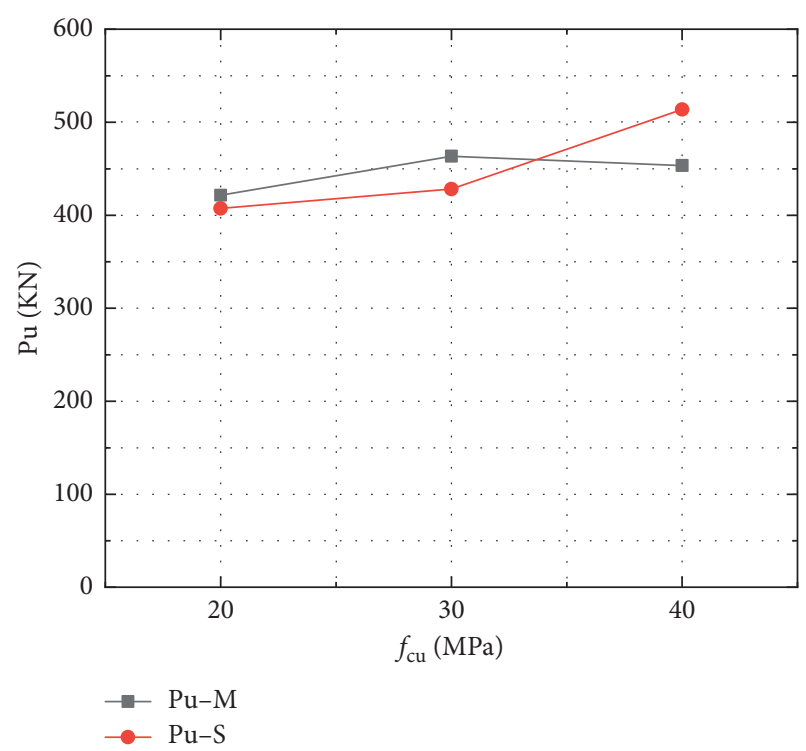

FIGURE 9: Effect of $f_{\text {cu }}$ on the specimen capacity.

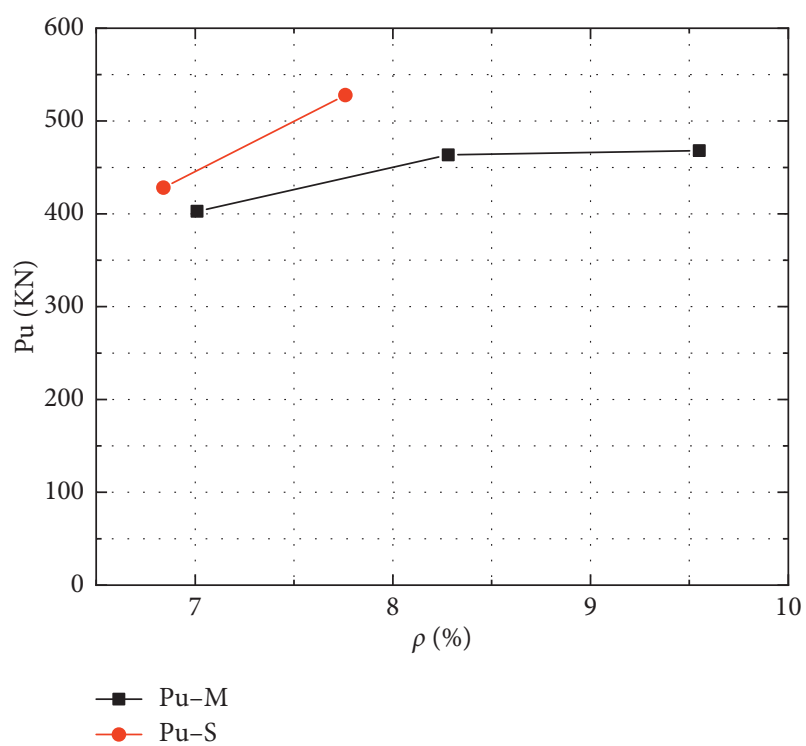

FIgURE 10: Effect of the steel ratio on the specimen capacity.

capacity or the shear capacity caused by the manufacturing method were less than $11 \%$.

\section{Analysis of the Bearing Capacity}

4.1. Flexural Capacity. Based on the plasticity theory [13] and the assumption of a plane section, the design method of flexural capacity of PEC beams was proposed in [14]. From the previous analysis, it was known that the difference between the flexural capacity of the PPEC beams and that of the PEC beams is small, so the flexural capacity of the PPEC beams could still be calculated by the method proposed in [14]. As shown in Table 3, the calculated results were in good agreement with the experimental results. The theoretical flexural capacity divided by the experimental flexural 


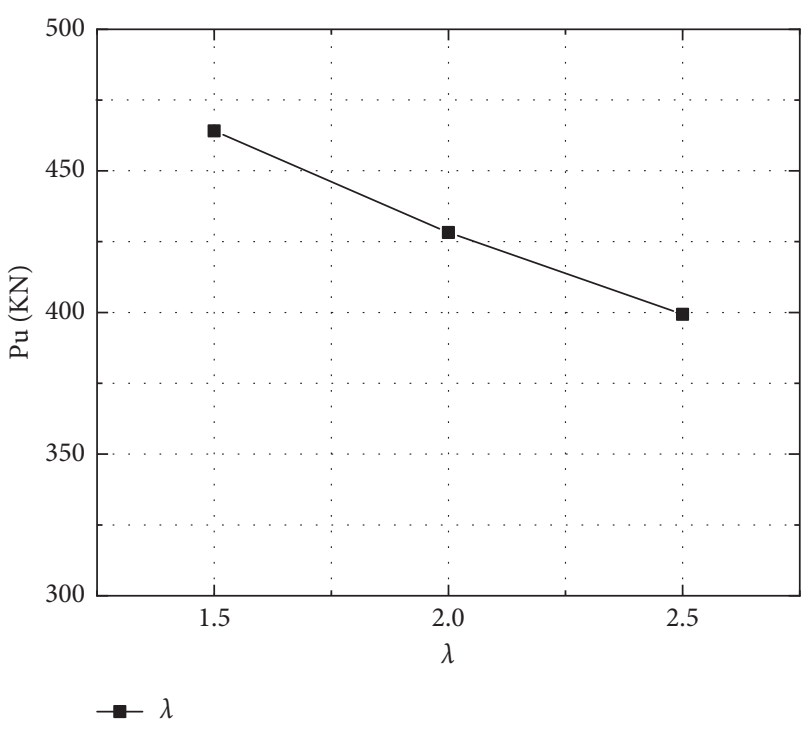

Figure 11: Effect of $\lambda$ on the shear capacity.

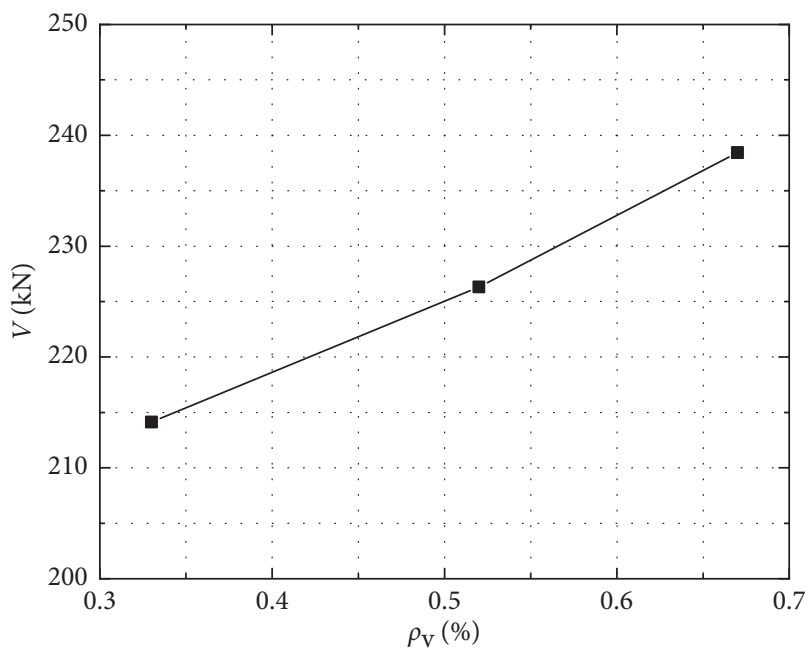

Figure 12: Effect of the stirrup ratio on the shear capacity.

capacity was 0.95 and the coefficient of variation was 0.05 . The calculation accuracy of this method is good, and it can be used as a reference for practical engineering design.

4.2. Shear Capacity. The calculation model of the shear capacity of the PPEC beams is shown in Figure 14. Based on Chinese code JGJ138-2016 [15] and the characteristics of PPEC beams, the shear capacity formula for PPEC beams was improved upon. The improvement ideas are described in the following:

(1) In the cross section of the PPEC composite beam, the precast concrete section occupied a considerable proportion. The calculation based on the small castin-place concrete strength grade was too conservative, and the shearing effect of the cast-in-place and precast two-part concrete needed to be considered reasonably. Using the area as the weight, the

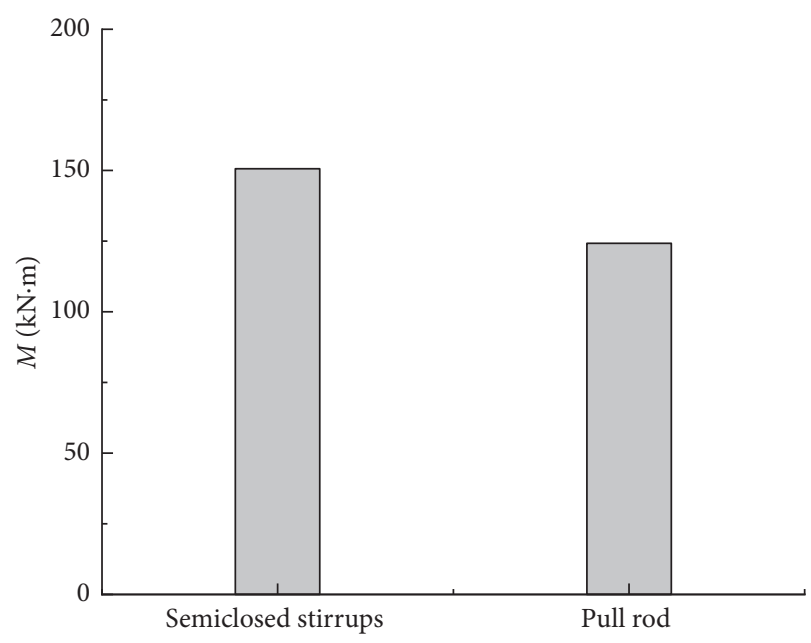

FIGURE 13: Effect of the stirrup form on the moment capacity.

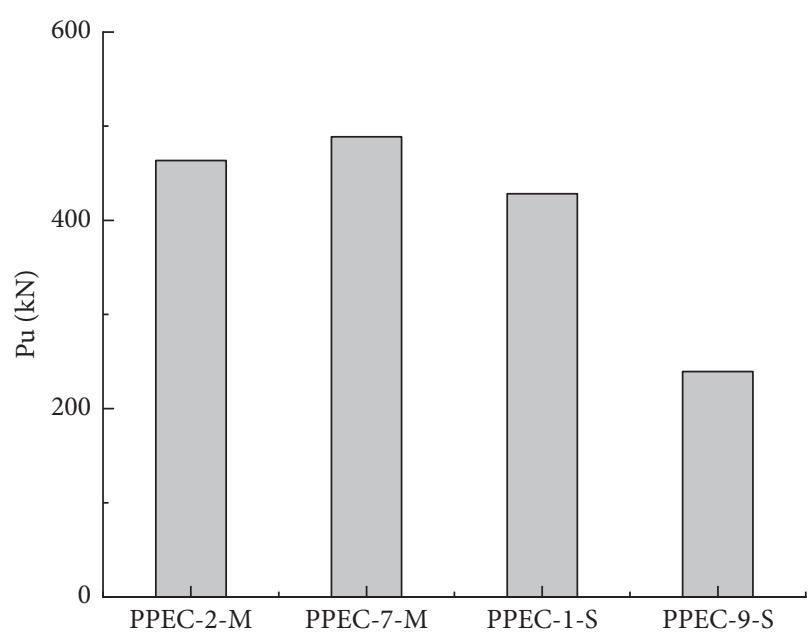

FIGURE 14: Effect of the construction technology on the specimen capacity.

weighted average method was used to obtain the converted concrete strength, as follows:

$$
f_{t, \mathrm{com}}=\frac{A_{c 1}}{A_{c 1}+A_{c 2}} f_{t 1}+\frac{A_{c 2}}{A_{c l}+A_{c 2}} f_{t 2}
$$

where $f_{t, \text { com }}$ is the conversion of the concrete tensile strength, $A_{c 1}$ and $f_{t 1}$ are the cast-in-place concrete area and the tensile strength, $A_{c 2}$ and $f_{t 2}$ are precast concrete area and the tensile strength, and the tensile strength is $f_{t}=0.26 f_{\mathrm{cu}}^{2 / 3}$.

(2) In the shear specimens, the concrete flange was in a state of shear-compression force. The concrete flange in the compression zone contributed to the shear capacity of the inclined section. This has been proven in paper [16]. Hence, the contribution of the concrete flange needed to be considered in the calculation of the shear capacity of the PPEC beam. The effect of the 
TABLE 3: The theoretical values versus the test values of the flexural capacity.

\begin{tabular}{lccc}
\hline No. & Theoretical value $(\mathrm{kN} \cdot \mathrm{m})$ & Test value $(\mathrm{kN} \cdot \mathrm{m})$ & Theoretical value/test value \\
\hline PECB-1-M & 117.10 & 130.90 & 0.90 \\
PPEC-2-M & 136.72 & 150.64 & 0.91 \\
PPEC-3-M & 152.20 & 152.14 & 1.00 \\
PPEC-4-M & 135.94 & 137.00 & 0.99 \\
PPEC-5-M & 141.73 & 147.39 & 0.96 \\
Average value & - & - & 0.95 \\
Variation coefficients & - & - & 0.05 \\
\hline
\end{tabular}

TABLE 4: The theoretical values versus the test values of the shear capacity.

\begin{tabular}{lccc}
\hline No. & Theoretical value $(\mathrm{kN} \cdot \mathrm{m})$ & Test value $(\mathrm{kN} \cdot \mathrm{m})$ & Theoretical value/test value \\
\hline PECB-1-S & 208.93 & 214.13 & 0.98 \\
PPEC-2-S & 275.80 & 263.94 & 1.04 \\
PPEC-3-S & 195.64 & 199.69 & 0.98 \\
PPEC-4-S & 230.44 & 232.07 & 0.99 \\
PPEC-5-S & 252.91 & 256.88 & 0.98 \\
PPEC-6-S & 222.51 & 203.63 & 1.09 \\
PPEC-7-S & 221.26 & 226.32 & 0.98 \\
PPEC-8-S & 228.13 & 238.44 & 0.96 \\
Average value & - & - & 1.00 \\
Variation coefficients & - & - & 0.045 \\
\hline
\end{tabular}

flange could be achieved with an amplification factor, which can be expressed as follows:

$$
\gamma_{\mathrm{f}}^{\prime}=\frac{\left(b_{\mathrm{f}}^{\prime}-b\right) h_{\mathrm{f}}^{\prime} f_{c 1}}{A_{c 1} f_{c 1}+A_{c 2} f_{c 2}}
$$

where $b_{\mathrm{f}}^{\prime}$ is the width of the concrete flange, $b$ is the PPEC beam width, $h_{\mathrm{f}}^{\prime}$ is the height of the concrete flange, $h$ is the height of the T beam, $h_{\mathrm{w}}$ is the height of the I-steel web, $f_{\mathrm{yv}}$ is the yield strength of the stirrup, $f_{\mathrm{y}}$ is the yield strength of the I-steel web, and $\lambda$ is the shear span ratio.

Referring to the expression of the shear capacity of a JGJ138 composite beam, combined with the analysis of the factors affecting the shear capacity described in the previous section, the shear capacity of a PPEC beam can be expressed as

$$
V_{u}=\frac{c \times\left(\gamma_{\mathrm{f}}^{\prime}+1.0\right)}{\lambda+d} f_{t, \mathrm{com}} b h+\frac{h_{\mathrm{w}} t_{\mathrm{w}} f_{\mathrm{y}}}{\sqrt{3}}+\frac{f_{\mathrm{yv}} A_{\mathrm{sv}}}{s} h .
$$

The regression analysis was carried out by the shear capacity values obtained by the test, and the values of $c$ and $d$ were 0.388 and 0.12 , respectively. The improved PPEC beam shear capacity calculation method was as follows:

$$
V_{u}=\frac{0.388\left(\gamma_{\mathrm{f}}^{\prime}+1.0\right)}{\lambda+0.12} f_{t, \mathrm{com}} b h+\frac{h_{\mathrm{w}} t_{\mathrm{w}} f_{\mathrm{y}}}{\sqrt{3}}+\frac{f_{\mathrm{yv}} A_{\mathrm{sv}}}{s} h .
$$

The shear capacity of the PPEC beam obtained according to the above method is shown in Table 4. The calculation results showed that the experimental values agreed well with the theoretical values. The theoretical shear capacity divided by the experimental shear capacity was 1.00 , and the coefficient of variation was 0.045 . This proves that the proposed formula for calculating the shear capacity is effective and it can be used as a reference for practical engineering.

In summary, the mechanical properties of the PPEC beams proposed in this paper are excellent. Based on the experimental analysis, the corresponding flexural and shear capacity design methods were proposed. The results showed that the calculated results were in good agreement with the experimental results, which had certain guiding significance for the practical application and popularization of this kind of composite beam.

\section{Concluding Remarks}

Through an experimental study of the mechanical properties of fourteen T-shaped PPEC beams and two T-shaped PEC beams, the following conclusions were drawn:

(1) The improved PPEC beam structural form proposed in this paper is generally feasible. The I-steel, cast-inplace concrete, and precast concrete worked well together without obvious slips.

(2) Compared with the cast-in-place PEC beams, the PPEC beams had the same failure mode and a similar bearing capacity. Prefabrication and casting-in-place had little effect on the mechanical properties of the specimens, especially in the elastic stage.

(3) With the increase of the concrete strength, the flexural and shear capacities of the PPEC beams were improved except for the flexural specimen of C40. With the increase of the steel ratio, the flexural and shear capacities of the PPEC beams increased. 
(4) With the increase of the shear span ratio, the shear capacity of the PPEC beams decreased gradually. With the increase of the stirrup ratio, the shear capacity of the PPEC beams increased gradually.

(5) Based on the test results, the design method of the shear capacity of the PPEC beams was presented. The results show that the test results were in good agreement with the calculation results, which can be used for reference in practical engineering design.

\section{Data Availability}

The data used to support the findings of this study are included within the article

\section{Conflicts of Interest}

The authors declare that they have no conflicts of interest.

\section{Acknowledgments}

The research described in this paper was financially supported by the Natural Science Foundation of Jiangxi Province of China (no. 20171BAB206053). The authors thank LetPub (http://www.letpub.com) for its linguistic assistance during the preparation of this manuscript.

\section{References}

[1] Z. Bangfan, JPA Prefabricated Architecture Technology Integration Vol. 1 General Introduction to Prefabricated Architecture, China Construction Industry Press, Beijing, China, 2012.

[2] Z. Li, X. Zhang, and Y. Ding, "Seismic behavior of joints of prefabricated steel reinforced concrete integral frame," Journal of Building Structures, vol. 4, pp. 32-38, 2005.

[3] W.-P. Cheng, Y.-P. Song, and Z. Xiu-Juan, "Experiment study of bearing capacity for beam and column joints of precast and discontinuous steel reinforced concrete," Journal of Dalian Jiaotong University, vol. 35, no. 4, pp. 52-55, 2014.

[4] W.-P. Cheng, Y.-P. Song, and J. Wang, "Experimental study of seismic performance for interior beam-column joints of precast and discontinuous steel reinforced concrete frames," Journal of Dalian University of Technology, vol. 55, no. 2, pp. 171-178, 2015.

[5] EN 1994-1-1 Eurocode 4, Design of Composite Steel and Concrete Structures-General Rules End Rules for Buildings, CEN (European Committee for Standardization), Brussels, Belgium, 2004.

[6] J. He, Y. Liu, A. Chen, D. Wang, and T. Yoda, "Bending behavior of concrete-encased composite I-girder with corrugated steel web," Thin-Walled Structures, vol. 74, pp. 70-84, 2014.

[7] J.-K. Ahn and C.-H. Lee, "Fire behavior and resistance of partially encased and slim-floor composite beams," Journal of Constructional Steel Research, vol. 129, pp. 276-285, 2017.

[8] R. Kindmann, R. Bergmann, L. G. Cajot, and J. B. Schleich, "Effect of reinforced concrete between the flanges of the steel profile of partially encased composite beams," Journal of Constructional Steel Research, vol. 27, no. 1-3, pp. 107-122, 1993.
[9] S.-I. Nakamura and N. Narita, "Bending and shear strengths of partially encased composite I-girders," Journal of Constructional Steel Research, vol. 59, no. 12, pp. 1435-1453, 2003.

[10] S. Ahmad, A. Masri, and Z. Abou Saleh, "Analytical and experimental investigation on the flexural behavior of partially encased composite beams," Alexandria Engineering Journal, vol. 57, no. 3, pp. 1693-1712, 2018.

[11] Y. Jiang, X. Hu, W. Hong, and B. Wang, "Experimental study and theoretical analysis of partially encased continuous composite beams," Journal of Constructional Steel Research, vol. 117, pp. 152-160, 2016.

[12] Y. Chen, W. Li, and C. Fang, "Performance of partially encased composite beams under static and cyclic bending," Structures, vol. 9, pp. 29-40, 2017.

[13] China Architecture \& Building Press, GB 50017-2017 Standard for Design of Steel Structures, China Architecture \& Building Press, Beijing, China, 2016.

[14] Y. Jiang, X. Hu, W. Hong, M. Gu, and W. Sun, "Investigation on partially concrete encased composite beams under hogging moment," Advances in Structural Engineering, vol. 20, no. 3, pp. 461-470, 2017.

[15] China Architecture \& Building Press, JGJ138-2016 Code for Design of Composite Structures, China Architecture \& Building Press, Beijing, China, 2016.

[16] Y. Yong, Y. U. Yunlong, Y. Yang et al., "Experimental study on shear performance of partially precast steel reinforced concrete beams," Journal of Building Structures, vol. 38, no. 6, pp. 53-60, 2017. 


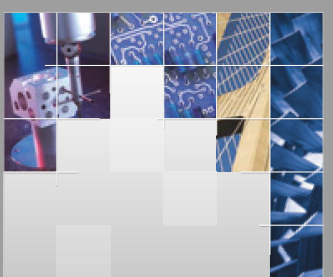

\section{Enfincering}
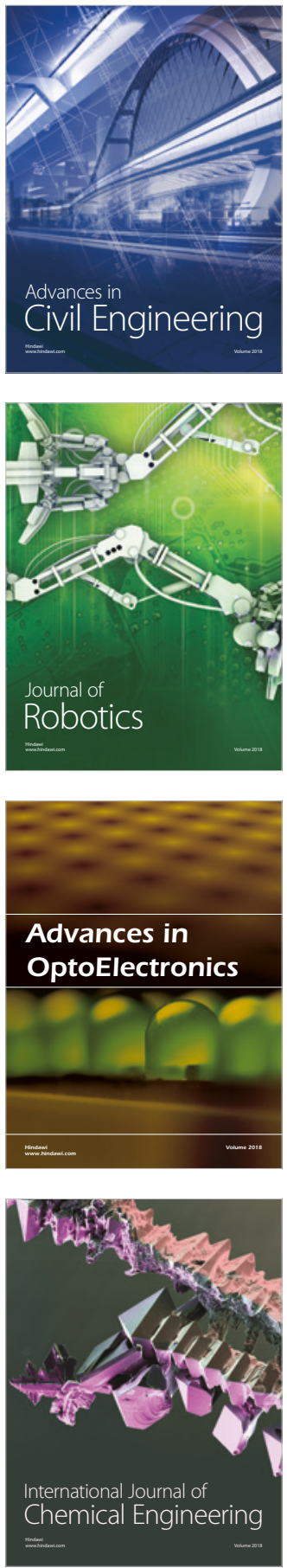

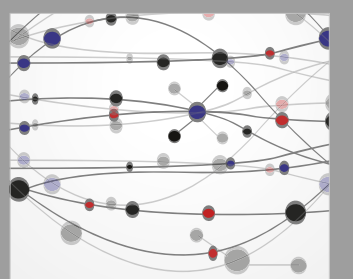

\section{Rotating \\ Machinery}

The Scientific World Journal

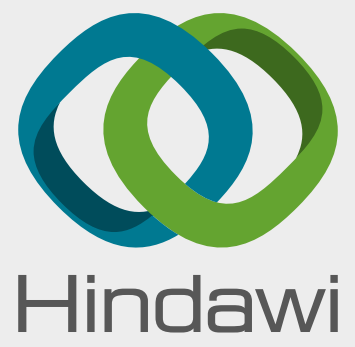

Submit your manuscripts at

www.hindawi.com
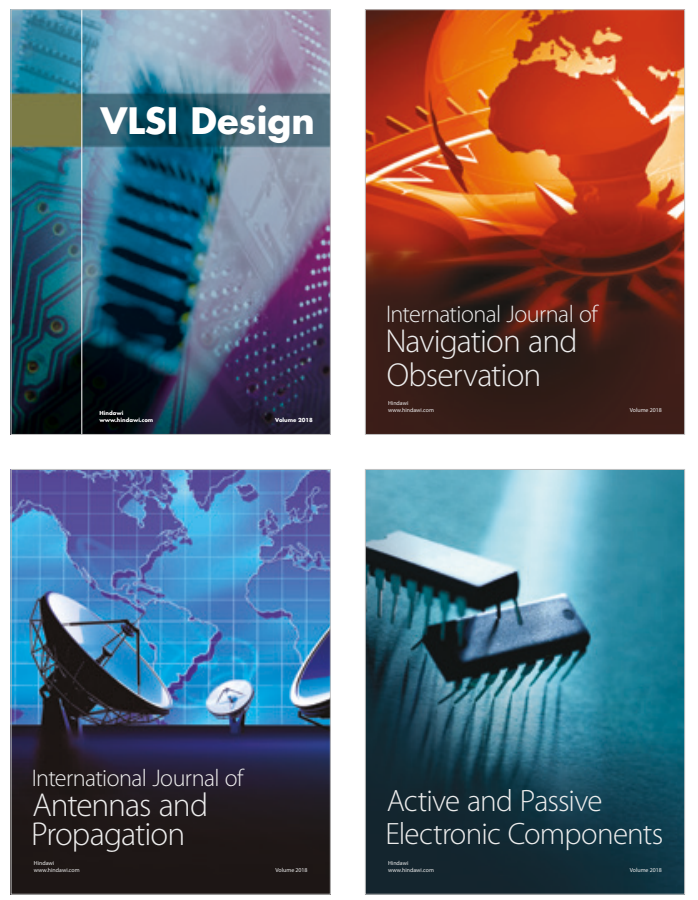
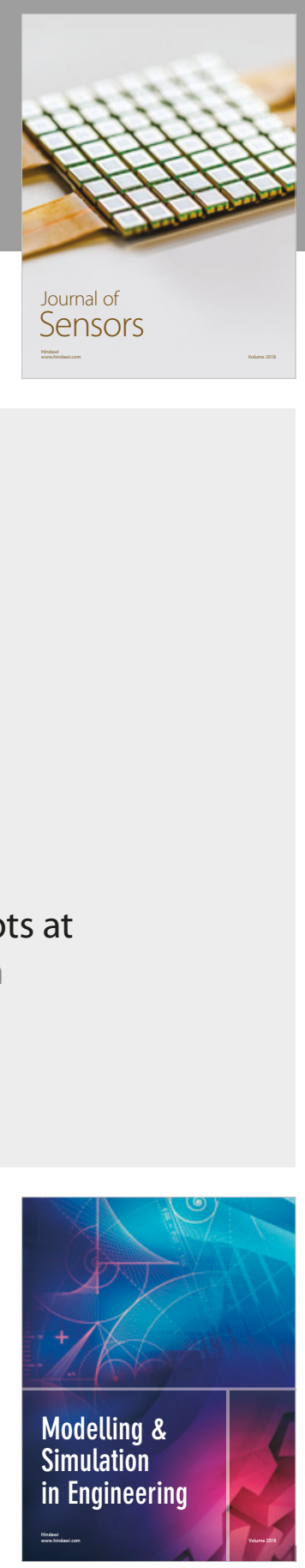

\section{Advances \\ Multimedia}
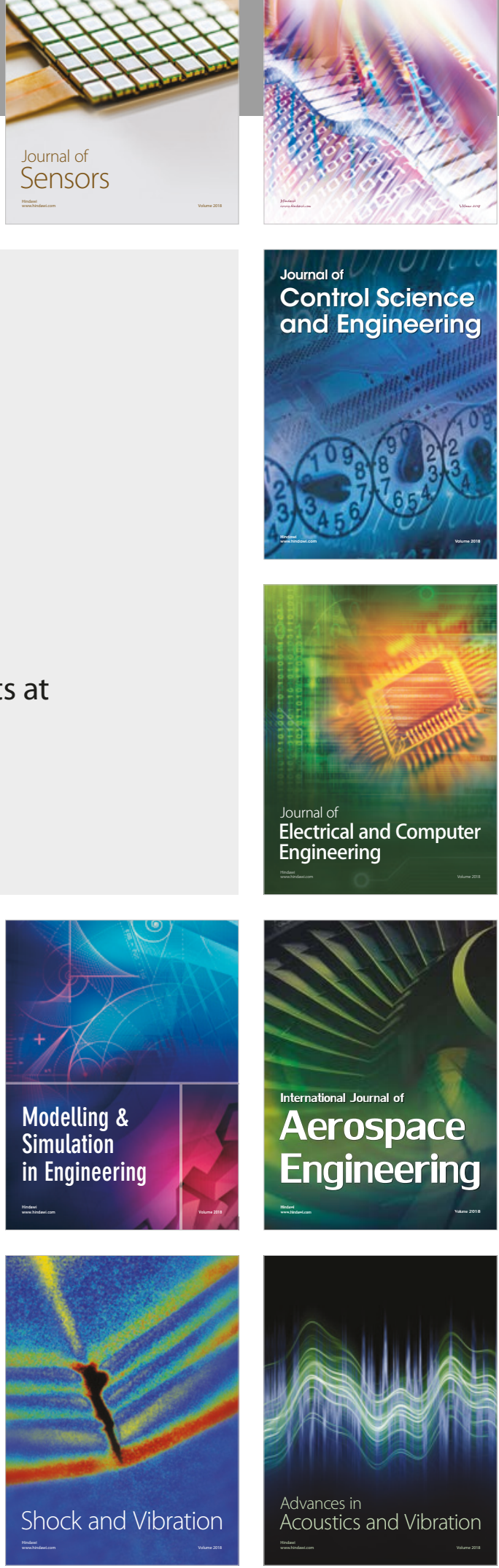